\title{
Extração e caracterização de pectinametilesterase (PME) de resíduos agroindustrais de abacaxi 'Pérola'
}

\section{Extraction and characterization of the pectin methylesterase (PME) of waste agroindustrial of the pineapple 'Pérola'}

\author{
Elck Almeida Carvalho ${ }^{1}$; Biano Alves de Melo Neto ${ }^{1 *}$; Heinz Johann Holschuh ${ }^{2}$; \\ Marcelo Franco ${ }^{3}$; Célio Kersul do Sacramento ${ }^{4}$
}

\begin{abstract}
Resumo
Objetivou extrair e caracterizar pectinametilesterase (PME) de resíduos industriais de abacaxi 'Pérola'. Foram determinadas a atividade específica, as condições ótimas de $\mathrm{pH}$ e temperatura, bem como a estabilidade térmica da PME concentrada (PME-C) e PME parcialmente purificada (PME-PP). A atividade específica da PME foi de 6,36 U/MG. O pH ótimo da PME extraída foi 8,5, classificada como alcalina. Durante o tempo de ensaio, a PME-PP manteve-se estável mediante exposição a temperaturas entre 25 e $60^{\circ} \mathrm{C}$, obtendo uma elevação da atividade em 40 e $50^{\circ} \mathrm{C}$. Em temperaturas superiores a $70^{\circ} \mathrm{C}$, houve uma redução na atividade específica. A PME-PP mostrou três bandas no gel poliacrilamida SDS-PAGE de massas molares aparentes (MM) de 25,4 e 23,1 kDa e 16,4 kDa. Os resultados obtidos demonstram ser possível explorar o potencial de uso da PME extraída a partir do subproduto do processamento de abacaxi 'Pérola'. Esta enzima está presente em praticamente todas as preparações enzimáticas comerciais para proteção e melhoramento da textura e firmeza de frutas e vegetais processados, na extração e clarificação de sucos de frutas. Atualmente, são importadas e tem elevado custo.
\end{abstract}

Palavras-chave: Purificação, pectinametilesterase, abacaxi, resíduo agroindustrial

\begin{abstract}
The objective was to obtain and characterize pectinmethylesterase (PME) of industrial residue from the Pearl Pineapple. Specific activities, the optimum conditions of $\mathrm{pH}$ and temperature, and also the thermal stability partially purified and concentrated PME were determined. The PME specific activity was 6.36 $\mathrm{U} / \mathrm{mg}$. The $\mathrm{pH}$ optimum of 7.5 PME was extracted, also considering alkaline. During the trial time, the partially purified PME maintained itself stable upon exposure to the temperatures of 25 and $60^{\circ} \mathrm{C}$. It obtained an activity elevation between 40 and $50^{\circ} \mathrm{C}$. In temperatures above $70^{\circ} \mathrm{C}$, there was a substantial reduction in a specific activity. The partially purified PME showed three gel polyacrylamide SDS-PAGE bands of apparent molar mass (MM) of 25.4 and $23.1 \mathrm{kDa}$ and $16.4 \mathrm{kDa}$. These results demonstrate the feasibility of PME extraction from the Pearl Pineapple's processed residue and its potential for use in manufacturing pulp and fruit juices, since the currently applied enzymes are imported and expensive.

Key words: Purification, pectinmethylesterase, pineapple, agro-industrial waste
\end{abstract}

\footnotetext{
${ }^{1}$ Profs. do Núcleo de Tecnologia de Alimentos, Instituto Federal Baiano/Campus Uruçuca, Rua Dr. João do Nascimento, s/nº, CEP 45.680-970, Uruçuca, BA. E-mail: elckcarvalho@gmail.com; biano.neto@gmail.com

${ }^{2}$ Prof. Adjunto, Dept ${ }^{\circ}$ de Tecnologia Química e de Alimentos, Universidade Federal da Paraíba, Campus Universitário I, CEP 58.051-900, João Pessoa, PB. E-mail: hj.holschuh@ct.ufpb.br

${ }^{3}$ Prof. Adjunto, Dept ${ }^{\circ}$ de Ciências Exatas e Tecnológicas, Universidade Estadual de Santa Cruz, BR - 415, Rodovia Ilhéus/Itabuna, km 16, CEP 45.662-900, Ilhéus, BA. E-mail: marcelofranco@pq.cnpq.br

${ }^{4}$ Prof. Pleno, Universidade Estadual de Santa Cruz, BR - 415, Rodovia Ilhéus/Itabuna, km 16, CEP 45.662-900, Ilhéus, BA. E-mail:kersul@uesc.br

* Autor para correspondência
} 


\section{Introdução}

O promissor mercado de enzimas vem substituindo o uso de substâncias químicas em diversos processos industriais e movimenta cerca de US\$ 10 bilhões em todo o mundo. Atualmente a quase totalidade das enzimas utilizadas em processos industriais no Brasil provém de importações. Em 2011 o país importou cerca de 10 mil toneladas do produto, utilizando recursos que ultrapassaram os US\$ 120 milhões de dólares (RAMOS, 2012; BRASIL, 2012).

Atualmente as pectinases correspondem a aproximadamente $25 \%$ do mercado mundial de enzimas e está presente em praticamente todas as preparações enzimáticas comerciais para proteção e melhoramento da textura e firmeza de frutas e vegetais processados e na extração e clarificação de sucos de frutas. A produção de pectinases é conduzida por empresas localizadas na Europa (60\%), Estados Unidos e Japão (40\%). Essas enzimas são produzidas por plantas superiores, fungos filamentosos, algumas bactérias e poucas leveduras, deste modo existem a possibilidade de aproveitar as biomassas obtidas a partir dos resíduos produzidos na agroindústria para a produção de enzimas. É possível efetuar a extração de pectinases a partir de subprodutos originados nas indústrias de alimentos, que pode reduzir os custos de produção e representar uma alternativa de lucro, além de oferecer uma alternativa de aproveitamento de subprodutos (HOONDAL, 2002; RESENDE et al., 2004; PELIZER; PONTIERI; MORAES, 2007; UENOJO; PASTORE, 2007; GALEMBECK; BARBOSA; SOUSA, 2009; MACÁRIO et al., 2009; MILETIC et al., 2009).

Em 2010, o Brasilocupou a segunda posição como produtor mundial de abacaxi, com aproximadamente 1,5 milhões de toneladas colhidas em área superior a 55 mil hectares plantados. Em termos nacionais, a produção tem sido concentrada no abacaxi da variedade Pérola, com área plantada correspondente a $80 \%$ do total nacional. A elaboração de alimentos e/ ou produtos minimamente processados que utilizam como matéria-prima o abacaxi implica na geração de elevadas quantidades de resíduos vegetais. Estes correspondem a aproximadamente $40 \%$ do peso total da matéria-prima processada, além de aumentar o custo operacional para as empresas e muitas vezes torna-se uma fonte de contaminação ambiental. A maioria dos estudos sobre a utilização dos resíduos do despolpamento do abacaxi tem sido direcionada à adubação e alimentação animal. Ainda assim, grande parte desse subproduto da indústria de alimentos tem sido destinado ao descarte (cerca de 85\%), sendo pequena parte disponibilizada para a alimentação animal na forma de componente de rações mistas (aproximadamente $15 \%$ ), procedimentos que levam a perdas não só econômicas e ambientais como biotecnológicas para a indústria de alimentos (IBGE, 2012; PRADO et al., 2003; OLIVEIRA et al., 2005; ROGÉRIO et al., 2007; OLIVEIRA et al., 2009).

O presente trabalho teve como objetivo extrair e caracterizar a enzima pectinametilesterase (PME) concentrada e parcialmente purificada extraídas dos resíduos da industrialização do abacaxi (Ananas comosus L. Merr) cv. Pérola.

\section{Materiais e Métodos}

\section{Subproduto de abacaxi}

As amostras de resíduos do processamento de abacaxi 'Pérola' (polpa, cascas e talos) utilizadas neste trabalho foram fornecidas pela indústria de sucos concentrados INTRAFRUT, localizada no município de João Pessoa - PB. Foram coletadas em datas diferentes de processamento e armazenadas à temperatura de $4^{\circ} \mathrm{C}$.

\section{Extração e purificação da enzima}

As enzimas foram extraídas na presença de tampão fosfato de sódio $0,2 \mathrm{M}, \mathrm{pH} 8,0$, contendo $0,5 \mathrm{M}$ de $\mathrm{NaCl}$. A relação do material com o tampão foi de $1: 3(\mathrm{~g} / \mathrm{mL})$. Para extração a mistura (resíduo+tampão) foi mantida refrigerada a $4{ }^{\circ} \mathrm{C}$ 
e sob leve agitação por 24 horas. A mistura foi centrifugada, com rotação de $5.000 \mathrm{~g} / 20$ minutos, para a remoção das partículas suspensas. O precipitado foi descartado e o sobrenadante denominado extrato bruto. As proteínas do extrato bruto foram precipitadas através da adição de sulfato de amônio na faixa de 60 a $80 \%$ de saturação conforme descrito por Collowich e Kaplan (1955). O extrato resultante da precipitação em sulfato de amônio foi submetido à diálise em: água destilada (por dois períodos de 4 horas) e em tampão fosfato de sódio 0,2 M, pH 8,0 (por dois períodos de 12 horas) e passou a denominar-se extrato concentrado (PME-C). O extrato concentrado foi aplicado na coluna de gel SEPHADEX G-100 a uma razão de 1\% do volume total (100 mL), com dimensões de $1,8 \mathrm{x}$ $30 \mathrm{~cm}$, equilibrada previamente com tampão fosfato $0,02 \mathrm{M}, \mathrm{pH} \mathrm{8,0}$ e com fluxo constante de $5 \mathrm{ml} / \mathrm{h}$. Frações de 3,0 mL foram coletadas e a absorbância lida a $280 \mathrm{~nm}$ em espectrofotômetro UV/vis marca Quimis. As frações obtidas foram denominadas extrato parcialmente purificado (PME-PP).

\section{Caracterização da Enzima}

\section{Atividade da Pectinametilesterase (PME)}

O ensaio de atividade da PME foi realizado como descrito por Hangermann e Austin (1986), com modificações de Lohani, Trivedi e Nath (2004). A mistura de reação foi preparada em um tubo de ensaio contendo $2 \mathrm{~mL}$ de solução de pectina $(0,01 \%$ solução aquosa, ajustando-se a $\mathrm{pH} 7,5 \mathrm{com} \mathrm{NaOH}$ $0,1 \mathrm{~N}), 0,4 \mathrm{~mL} \mathrm{NaCl} 0,15 \mathrm{M}, 0,2 \mathrm{~mL}$ de solução azul de bromotimol a $0,01 \%, 0,4 \mathrm{~mL}$ de água e $0,1 \mathrm{~mL}$ do homogenato. $\mathrm{O}$ tubo foi suavemente agitado e a absorbância medida imediatamente a $620 \mathrm{~nm}$. A absorbância foi medida novamente depois de decorridos 3 minutos. Através da diferença em absorbância entre 0 e 3 minutos foi calculada a atividade de PME na amostra. O cálculo da atividade foi realizado de acordo com a curva padrão descrito por Hangermann e Austin (1986). A unidade (U) foi definida como a quantidade da enzima requerida para liberar $1 \mu \mathrm{mol}$ de ester metil por minuto. Todas as leituras foram feitas em triplicata. A quantidade de proteína (mg) foi determinada de acordo com o método descrito por Lowry et al. (1951), usando albumina de soro bovino (Sigma Chemical Co., St. Louis, MO) como o padrão. Com base nos resultados da atividade enzimática e quantificação da proteína, a atividade específica foi calculada pela razão:

$\mathrm{AE}=$ Atividade Enzimática (U) /quantidade de proteínas (mg)

$\mathrm{U}$ : unidade de atividade enzimática

Determinação do pH, temperatura ótima e termoestabilidade

A atividade do extrato enzimático da PME-C e PME-PP foi analisada na faixa de $\mathrm{pH}$ de 5,0 a 9,5, com variação de 0,5 unidades. Estes extratos foram submetidos à reação nas temperaturas de 25 a $90^{\circ} \mathrm{C}$, com variação de $5^{\circ} \mathrm{C}$. Os testes de termoestabilidade foram conduzidos em temperaturas que variaram entre 25 a $80^{\circ} \mathrm{C}$ e incubação por intervalos de tempo variando entre 10 a $60 \mathrm{~min}$. Na temperatura de $90^{\circ} \mathrm{C}$ foram feitos testes com incubação por intervalos de tempo entre 1 e $9 \mathrm{~min}$, conforme metodologia descrita por Kashyap et al. (2001). Após o processo do aquecimento, os tubos foram refrigerados em "banho de gelo" por 30 minutos e a atividade residual determinada.

\section{Eletroforese}

Para identificar e monitorar proteínas durante as etapas de purificação, além de verificar o peso molecular e a homogeneidade das frações, utilizouse eletroforese em gel de poliacrilamida-dodecil sulfato de sódio (SDS-PAGE), conforme método descrito por Weber e Osborn (1969) e Laemmli (1970). As amostras provenientes da coluna cromatográfica foram concentradas por liofilização e posteriormente preparadas para eletroforese por mistura com tampão Tris-HCl $(\mathrm{pH} 8,8)$, solução 
de glicerina $20 \%$ e azul de bromofenol $0,001 \%$. Foram aplicados $10 \mu \mathrm{l}$ de amostras em condições desnaturante. $\mathrm{O}$ experimento foi conduzido usandose tampão Tris/glicina ( $\mathrm{pH} 8,3$ ), gel de concentração $3,5 \%$ e gel de separação a $12,5 \%$ de poliacrilamida, em cuba vertical (sistema Mini Protean II-BIORAD), empregando-se corrente de $150 \mathrm{~V}$ durante cerca de 2 horas, a $4^{\circ} \mathrm{C}$. Após o término da corrida, para a revelação das proteínas, utilizou-se a coloração com nitrato de prata (PORRO et al., 1982).

\section{Análises Estatísticas}

Os experimentos foram conduzidos com três repetições e os resultados submetidos à análise de variância - ANOVA e teste de Tukey a 5\%.

\section{Resultados e Discussão}

\section{Seleção da fração protéica}

Na Tabela 1 estão apresentados os resultados obtidos para as diferentes saturações de sulfato de amônio referente à recuperação da enzima PME por precipitação. Foi verificado que a fração com a saturação entre 60-80\% apresentou uma atividade específica (AE) de 6,36 U/mg, sendo superior e diferindo significativamente $(\mathrm{P}<0,05)$ das atividades específicas obtidas nas demais faixas. Por este motivo a fração proteica precipitada nesta faixa de saturação (60-80\%) foi utilizada para realização da purificação parcial em coluna de cromatografia e análises subsequentes.

Tabela 1. Atividade específica da PME nas diferentes faixas de precipitação de proteínas fracionadas através do sulfato de amônio.

\begin{tabular}{cccc}
\hline $\begin{array}{c}\text { Concentração de saturação } \\
\text { do sulfato de amônio }\end{array}$ & PME $(\boldsymbol{\mu m o l} / \mathbf{m L})$ & $\begin{array}{c}\text { Proteína } \\
(\mathbf{m g} / \mathbf{m L})\end{array}$ & $\begin{array}{c}\text { AE PME } \\
(\mathbf{U} / \mathbf{m g} \text { proteína)* }\end{array}$ \\
\hline $0-20 \%$ & 0,00 & 3,7 & $0,00^{\mathrm{d}}$ \\
$20-40 \%$ & 5,00 & 3,4 & $1,47^{\mathrm{c}}$ \\
$40-60 \%$ & 6,65 & 2,1 & $3,17^{\mathrm{b}}$ \\
$60-80 \%$ & 11,02 & 1,7 & $6,36^{\mathrm{a}}$ \\
$80-90 \%$ & 1,12 & 0,2 & $5,64^{\mathrm{a}}$ \\
\hline
\end{tabular}

*Valores seguidos por letras iguais na coluna não diferem entre si, pelo teste de Tukey, a 5\% de probabilidade.

Fonte: Elaboração dos autores.

\section{Purificação da PME}

$\mathrm{Na}$ Figura 1 pode ser observada a atividade específica (AE) da PME eluída da coluna de SEPHADEX G-100. Tais resultados sugerem a presença de isoenzimas de PME nas amostras. Dentre os picos de atividade específica observados, o de maior dimensão foi observado na fração de número 32 ou pico 3, indicando que nesta porção do eluído se encontravam a maior parte da enzima de interesse. Portanto essa fração foi selecionada para a continuidade das análises enzimáticas, sendo que esta foi denominada PME-PP. Na Tabela 2 estão apresentados os dados das etapas de purificação da PME. A PME-C e PME-PP obtiveram respectivamente fatores de purificação de 8,4 e 55,65 vezes, comparadas ao extrato bruto obtido inicialmente. O processo de purificação parcial aumentou a atividade específica (AE) em 6,56 vezes. Ly-Nguyen et al. (2002b), ao estudarem a PME em laranja e de morangos obtiveram, grau de purificação de 15,9 vezes, em relação ao extrato concentrado. 
Figura 1. Perfil de eluição de proteínas à 280nm e da PME em coluna de gel SEPHADEX G-100.

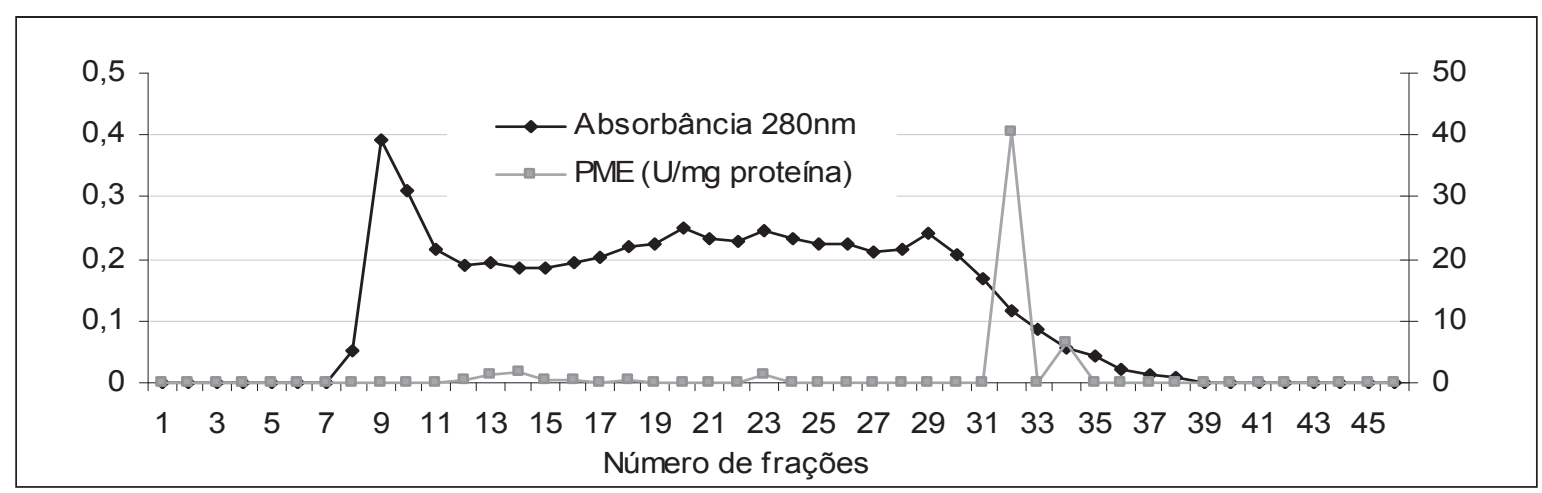

Fonte: Elaboração dos autores.

Tabela 2. Atividade da PME em diferentes etapas de purificação.

\begin{tabular}{|c|c|c|c|c|c|c|c|}
\hline Amostras & $\begin{array}{c}\text { Volume } \\
\text { (mL) }\end{array}$ & $\begin{array}{l}\mathrm{RC}^{\mathrm{a}} \\
(\%)\end{array}$ & $\begin{array}{c}\text { Atividade }^{\mathrm{b}} \\
\text { (U/mL) }\end{array}$ & $\begin{array}{c}\text { PTN }^{c} \\
(\mathrm{mg} / \mathrm{mL})\end{array}$ & $\begin{array}{c}\mathrm{AE}(\mathrm{U} / \\
\mathrm{mg})\end{array}$ & $\begin{array}{c}\text { FPd }^{\mathrm{d}} \text { (Ext. } \\
\text { Bruto) }\end{array}$ & $\begin{array}{c}\text { FP (Ext. } \\
\text { Conc.) }\end{array}$ \\
\hline Extrato Bruto & 1100,0 & 100 & 1,47 & 1,940 & 0,75 & 1,00 & - \\
\hline PME-C & 25,0 & 17,03 & 11,02 & 1,734 & 6,36 & 8,40 & 1,00 \\
\hline PME-PP & 75,0 & 0,55 & 0,12 & 0,003 & 41,74 & 55,65 & 6,56 \\
\hline
\end{tabular}

a) RC - Recuperação; b) Atividade enzimática expressa em $\mu \mathrm{mol}$ de grupos carboxílicos por minuto a $30^{\circ} \mathrm{C}$; c) PTN - Proteínas; d) FP - Fator Purificação

Fonte: Elaboração dos autores.

\section{Eletroforese}

A PME-PP apresentou três bandas em gel de poliacrilamida SDS-PAGE (Figura 2). Avisualização gráfica usando o software ImageMaster 1D (Amersham Biosciences, Suécia), baseado no padrão de proteínas, indicou duas faixas de intensidade semelhantes que correspondem as massas molares aparentes de 25,4 e 23,1 kDa e uma banda secundária de 16,4 kDa. Estudos das propriedades cinéticas de diferentes frutos têm mostrado que a PME ocorre em duas ou mais isoformas, cada uma possuindo uma única cadeia polipeptídica com pesos moleculares variando de 10 a $73 \mathrm{kDa}$ (PRASANNA; PRABHA; THARANATHAN, 2006). 
Figura 2. Eletroforese em gel de poliacrilamida SDS/PAGE em amostras de PME extraídas de resíduos do processamento de abacaxi 'Pérola'. (A) Padrão de massa molecular; (B) Amostra do extrato de PME-PP.

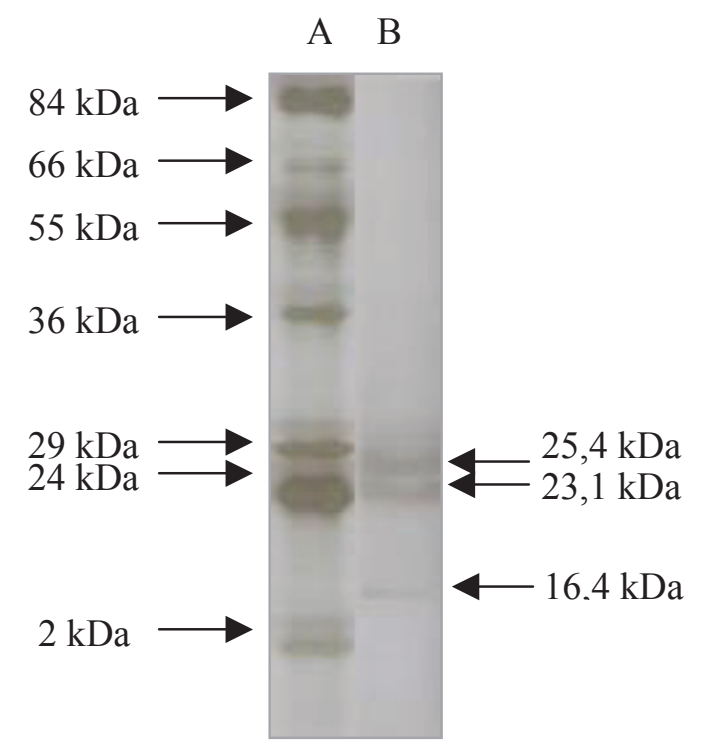

Fonte: Elaboração dos autores.

\section{Determinação do pH ótimo}

$\mathrm{O}$ valor de $\mathrm{pH}$ ótimo para atividade da PME-C e PME-PP encontra-se em 8,5 (figura 3). Mas observase também, na trajetória relacionada à PME-C, a sutil formação de um pico de atividade menor a $\mathrm{pH} 7,5$, parecendo indicar, novamente, a existência de isoenzimas no extrato concentrado. Em pH 5,0 ambas as amostras testadas (PME-C e PME-PP) demonstram apenas 7,6\% da sua atividade máxima. Valores similares foram relatados em estudos realizados em goiabas da variedade Paluma, cujo $\mathrm{pH}$ ótimo para atividade da enzima PME-C estava na faixa de 8,0 a 9,0, sendo observado para a enzima PME-PP um pico em pH 8,5 (LY-NGUYEN et al. 2002b; LEITE et al. 2006). Assis et al. (2004) relatou para a PME de acerola (Malpighia glabra L.) $\mathrm{pH}$ ótimo igual a 9,0. Amaral, Assis e Oliveira (2005) determinaram $\mathrm{pH}$ ótimo igual a 8,0 ao estudarem a atividade da PME em suco de laranja da variedade Pêra - Rio. Arbaisah et al. (1997), ao trabalharem com polpa de graviola (Anona muricata), obtiveram $\mathrm{pH}$ ótimo na faixa de 7,0-8,0. Ly-Nguyen et al. (2002a) encontraram pH ótimo em torno de 6,9 a 7,0 em PME de morangos.

\section{Determinação da temperatura ótima}

$\mathrm{Na}$ Figura 4, está apresentada a atividade enzimática $\left(\mathrm{U}_{\mathrm{mg}} \mathrm{m}^{-1}\right.$ ) em função da temperatura. Pode-se observar que a PME-C apresentou atividade máxima a $40^{\circ} \mathrm{C}$, diferindo da PME-PP, cuja temperatura foi $50^{\circ} \mathrm{C}$. Assis et al. (2004) estimou que a maioria das PME encontram-se ativas no intervalo de temperatura entre 40 e $50^{\circ} \mathrm{C}$. Há a possibilidade de que as isoenzimas com temperaturas ótimas inferiores tenham ficado em outras frações daquelas coletadas após a percolação do extrato dialisado na coluna de gel SEPHADEX G-100. Lim e Chung (1993) encontraram duas isoenzimas no estudo da PME em mamão papaia, obtiveram temperatura ótima de $35^{\circ} \mathrm{C}$ para ambas. Os estudos realizados para se determinar as temperaturas ótimas da PMEPP de frutas como morango, laranja da variedade Shamouti, goiaba Paluma e acerola (Malpighia glabra L.) observaram temperaturas superiores, $59,60,85$ e $90^{\circ} \mathrm{C}$, respectivamente (KÖRNER; ZIMMERMAN; BERK, 1980; ASSIS et al., 2004; LEITE et al., 2006). 
Figura 3. Efeito do $\mathrm{pH}$ na atividade do extrato de PME-C e da PME- PP.

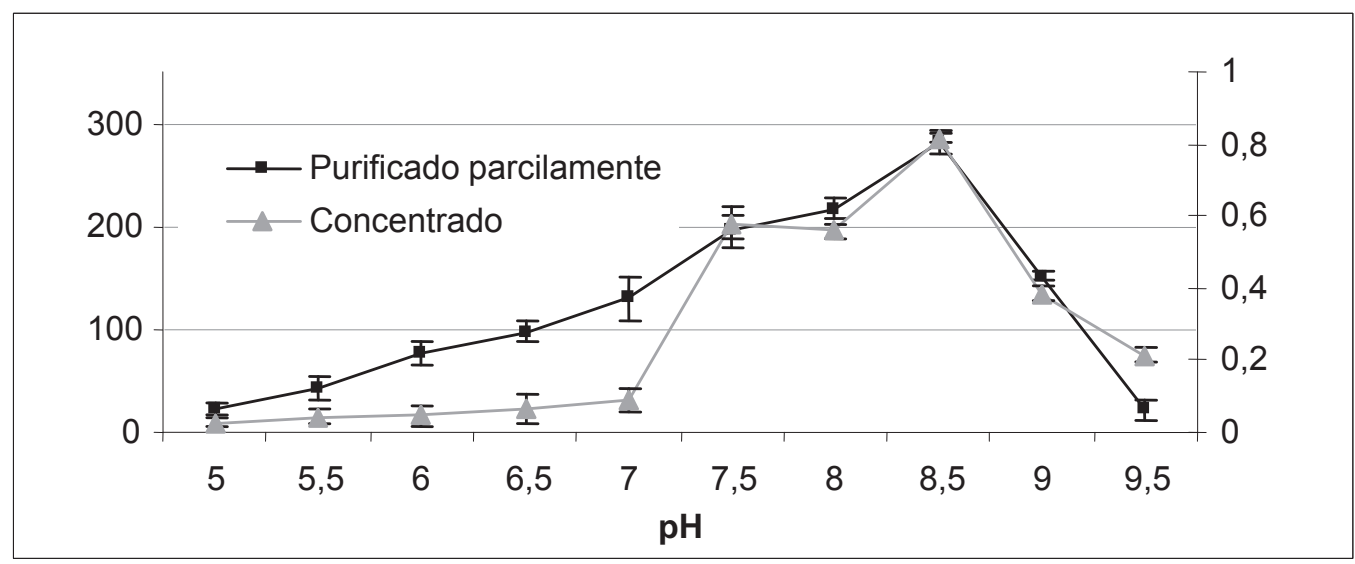

Fonte: Elaboração dos autores.

Figura 4. Efeito da temperatura na atividade da PME-C e da PME-PP.

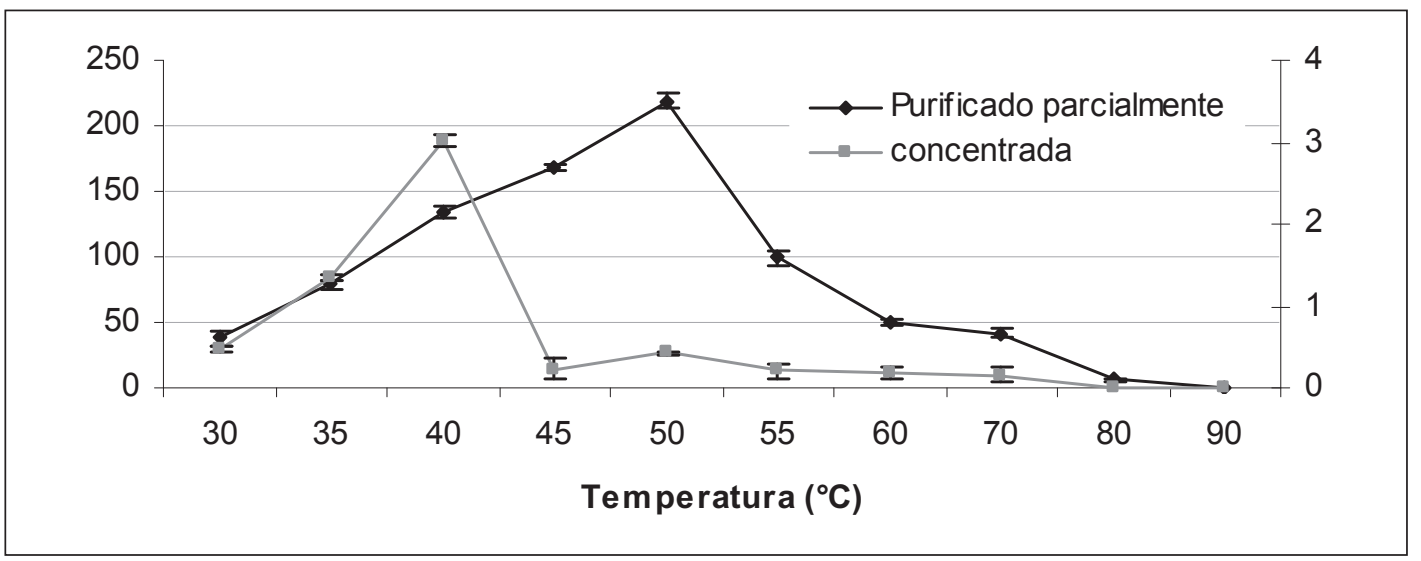

Fonte: Elaboração dos autores.

\section{Estabilidade térmica}

As atividades da PME-C e da PME-PP em função do tempo de incubação podem ser observadas nas Figuras 5 e 6, respectivamente. Na temperatura de $25^{\circ} \mathrm{C}$ a amostra de PME-C teve um comportamento diferenciado com acréscimo de $37,5 \%$ na atividade enquanto a atividade da PME-PP foi considerada estável durante a estocagem da amostra por 40 minutos. Nesta mesma temperatura aos 60 minutos de estocagem, a PME-C obteve acréscimo de 45,9\% relacionado à atividade inicial e a atividade da PMEPP mantiveram-se estável com pequena redução de
3,9\%. Leite et al. 2006, avaliando o comportamento da polpa de goiaba Paluma a $75^{\circ} \mathrm{C}$ observou um acréscimo de $64,77 \%$ na atividade enzimática da PME-C em relação à inicial. Quando as amostras foram levadas a $40^{\circ} \mathrm{C}$, a atividade enzimática apresentou um comportamento de acréscimo nas duas PME estudadas. É possível que a precipitação com sulfato de amônio tenha formado agregados enzimáticos inativos que ao serem aquecidos se dissociaram, aumentando aparentemente a atividade da fração. 
Figura 5. Atividade residual da enzima PME-C em diversas temperaturas e em função do tempo.

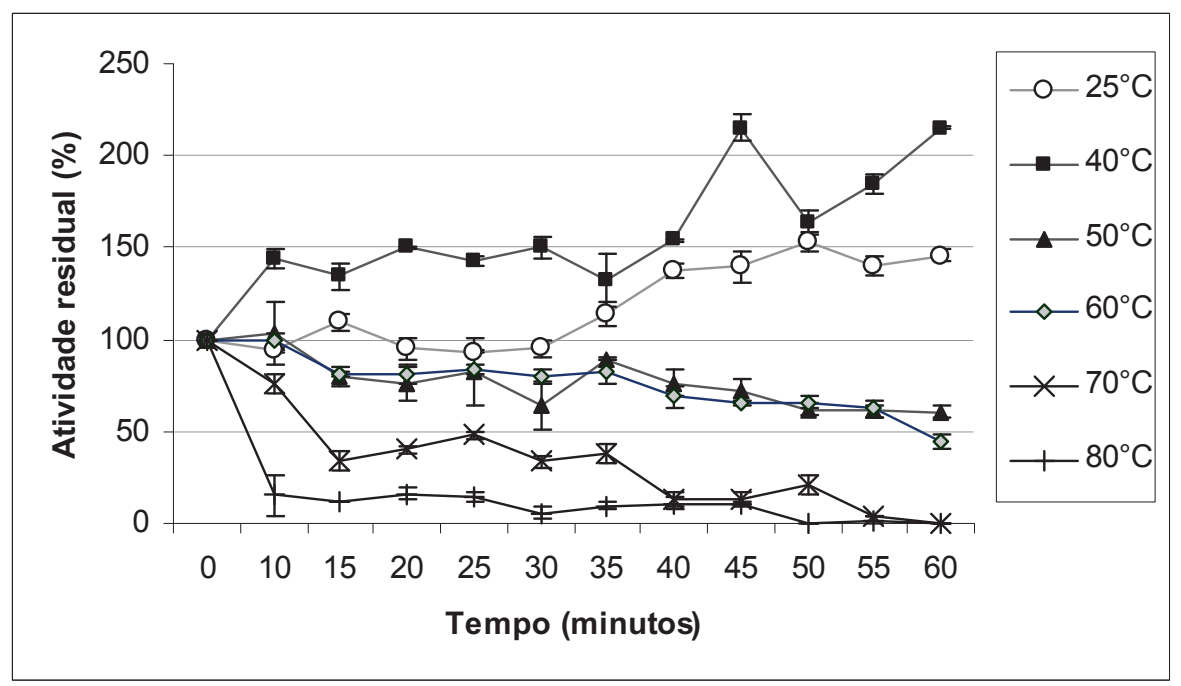

Fonte: Elaboração dos autores.

Figura 6. Atividade residual da enzima PME-PP em diversas temperaturas e em função do tempo.

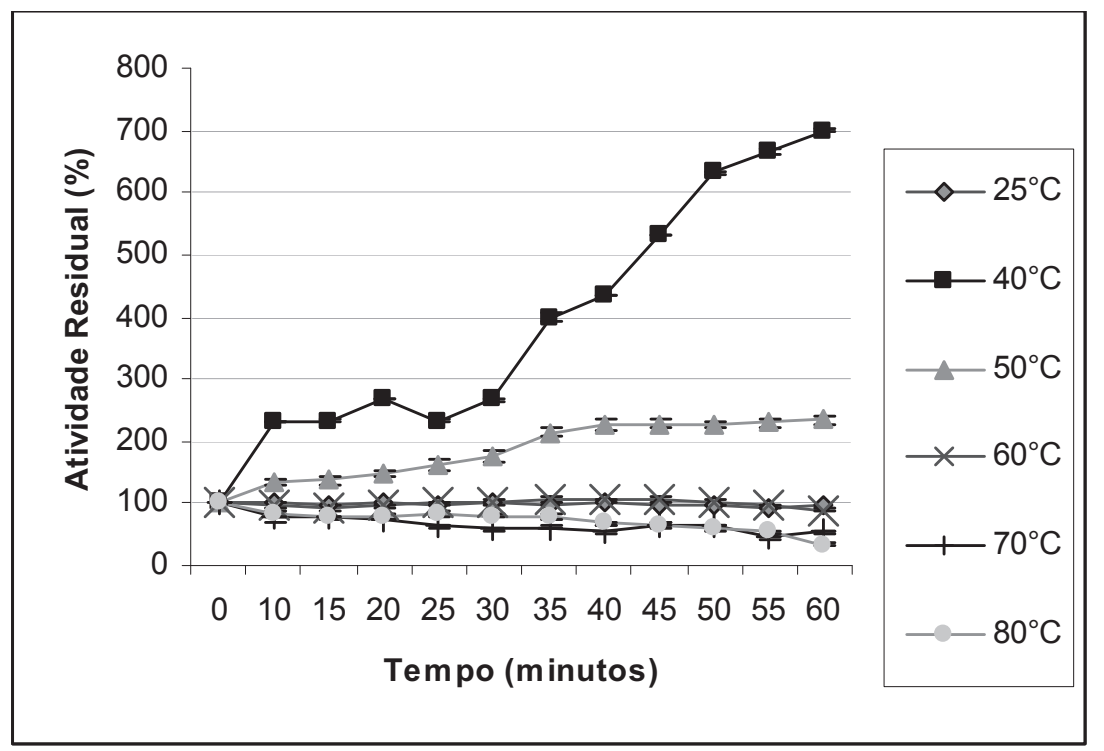

Fonte: Elaboração dos autores.

Na Figura 7 estão apresentadas as atividades residuais enzima PME-C e da PME-PP em função do tempo à temperatura de $90^{\circ} \mathrm{C}$. No primeiro minuto de estocagem de $90^{\circ} \mathrm{C}$ a amostra PME-PP apresentou redução de $44,0 \%$ na sua atividade, enquanto a concentrada tem sua inativação praticamente consumada dispondo somente de $16,6 \%$ de sua atividade inicial. A inativação completa de ambas as amostras foi alcançada após nove minutos de incubação nesta temperatura. Conhecer a termoestabilidade das enzimas permite a adição em produtos que no decorrer do processamento precisam passar por algum tratamento térmico sem inativação ou a inativação intencional desta enzima quando já se obteve o resultado esperado da sua atividade catalítica. 
Figura 7. Atividade residual do extrato PME-C e PME-PP em função do tempo e com a temperatura em $90^{\circ} \mathrm{C}$.

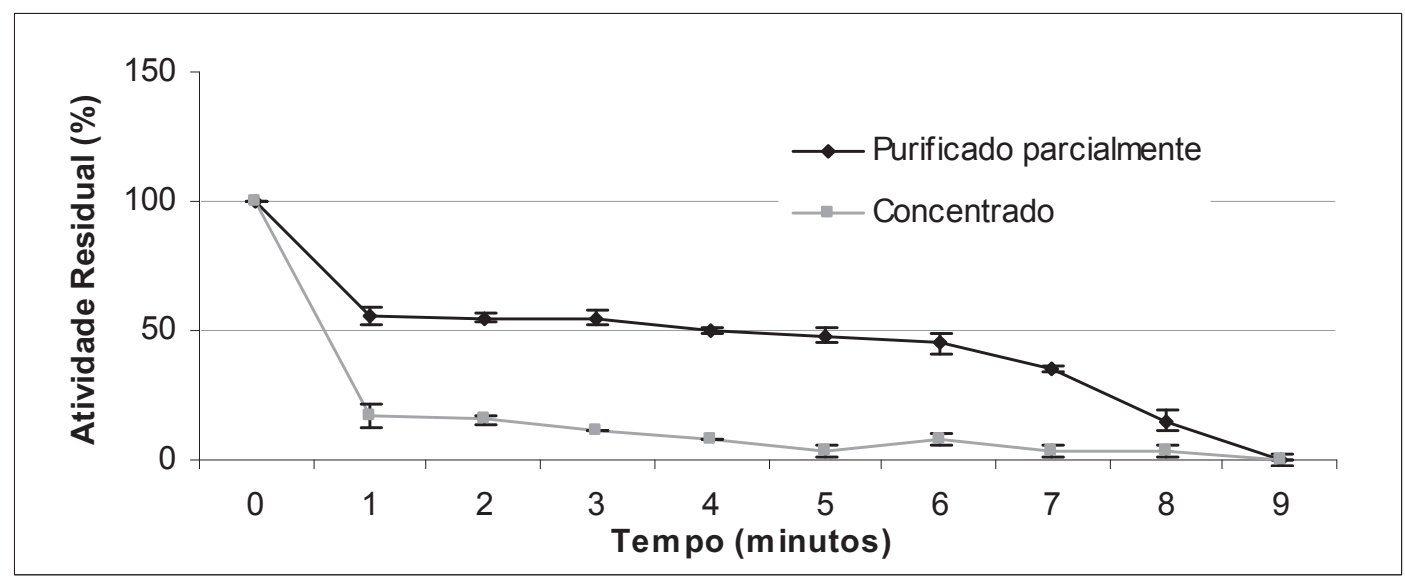

Fonte: Elaboração dos autores.

\section{Conclusões}

$\mathrm{O}$ pH ótimo da pectinametilesterase (PME) situa-se em faixa alcalina indicando que, a sua atividade pode ser reduzida através da acidificação. A atividade enzimática da PME-PP manteve-se estável até a temperatura de $60^{\circ} \mathrm{C}$. Esses resultados demonstram a viabilidade de extração da PME a partir dos resíduos industriais do abacaxi e sua potencialidade como coadjuvante tecnológico para a indústria de polpas e sucos de frutas, uma vez que as enzimas utilizadas são importadas e de alto custo.

\section{Agradecimentos}

A Fundação de Amparo à Pesquisa do Estado da Bahia (FAPESB) pelo apoio financeiro.

\section{Referências}

AMARAL, S. H.; ASSIS, S. A.; OLIVEIRA, O. M. M. F. Partial Purification and characterization of pectin methylesterase from orange (Citrus sinensis) cv. PeraRio. Journal of Food Biochemistry, Gainesville, v. 29, n. 4, p. 367-380, 2005.

ARBAISAH, S. M.; ASBI, B. A.; JUNAINAH, A. H.; JAMILAH, B. Purification and properties of pectinesterase from soursop (Anona muricata) pulp, Food Chemistry, Barking, v. 59, n. 1, p. 33-40, 1997.

ASSIS, S. A.; FERREIRA, B. S.; FERNANDES, P.; GUAGLIANONI, D. G.; CABRAL, J. M. S.; OLIVEIRA,
O. M. M. F. Gelatin-immobilized pectinmethylesterase for production of low methoxyl pectin, Food Chemistry, Barking, v. 86, n. 3, p. 333-337, 2004.

BRASIL. Ministério do Desenvolvimento, Indústria e Comércio Exterior. Aliceweb. 2012. Disponível em: $<$ www.mdic.gov.br>. Acesso em: 10 mar. 2012.

GALEMBECK, F.; BARBOSA, C. A. S.; SOUSA, R. A. Aproveitamento sustentável de biomassa e de recursos naturais na inovação química. Química Nova, São Paulo, v. 32, n. 3, p. 571-581, 2009.

HANGERMANN, A. E.; AUSTIN, P. J. Continuous spectrophotometric assay for plant pectin methylesterase. Journal of Agricicultural and Food Chemistry, Washington, v. 34, n. 3, p. 440-444, 1986.

HOONDAL, G. S.; TIWARI, R. P.; TEWARI, R.; DAHIYA, N.; BEG, Q. K. Microbial alkaline pectinases and their industrial applications: a review. Applied Microbiology and Biotechnology, Berlin, v. 59, n. 4-5, p. 409-418, 2002.

INSTITUTO BRASILEIRO DE GEOGRAFIA E ESTATÍSTICA - IBGE. Levantamento sistemático da produção agrícola. 2012. Disponível em: $<$ http://www.sidra.ibge.gov.br/bda/tabela/protabl. asp? $\mathrm{z}=\mathrm{peo}=22 \mathrm{ei}=\mathrm{p}>$. Acesso em: 11 set. 2012.

KASHYAP, D. R.; VOHRA, P. K.; CHOPRA, S.; TEWARI, R. Applications of pectinases in the commercial sector: a review. Bioresource Technology, New York, v. 77, n. 3, p. 215-227, 2001.

KÖRNER, B.; ZIMMERMAN, G.; BERK, Z. Orange pectinaesterase: purification, properties and effects on cloud stability, Journal of Food Science, Chicago, v. 45, n. 5, p. 1203-1206, 1980. 
LAEMMLI, U. K. Cleavage of structural proteins during the assembly of the head of bacteriophage T4. Nature, London, v. 227, n. 15, p. 680-685, 1970.

LEITE, K. M. S. C.; TADIOTTI, A. C.; BALDOCHI, D.; OLIVEIRA, O. M. M. F. O. Partial purification, heat stability and kinetic characterization of the pectinmethylesterase from Brazilian guava, Paluma cultivars. Food Chemistry, Barking, v. 94, n. 4, p. 565572, 2006.

LIM, Y. M.; CHUNG, M. C. M. Isolation and characterization of pectin methylesterase from papaya. Archives of Biochemistry and Biophysics, San Antonio, v. 307, n. 1, p. 15-20, 1993.

LOHANI, S.; TRIVEDI, P. K.; NATH, P. Changes in activities of cell wall hydrolases during ethylene-induced ripening in banana: effect of 1-MCP, ABA and IAA. Postharvest Biology and Technology, Washington, v. 31, n. 2, p. 119-126, 2004.

LOWRY, O. H.; ROSEBROUGH, N. J.; FARR, A. L.; RANDALL, R. J. Protein Measurement with the Folin Phenol Reagent. Journal of Biological Chemistry, Baltimore, v. 193, n. 1, p. 265-275, 1951.

LY-NGUYEN, B.; LOEY, A. V.; FACHIN, D.; VERLENT, I.; DUVETTER, T.; VU, S. T.; SMOUT, C.; HENDRICKX, M. E. Strawberry pectin methylesterase (PME): purification, characterization, thermal and highpressure inactivation.Biotechnology Progress, Pittsburgh, v. 18, n. 6, p. 1447-1450, 2002a.

LY-NGUYEN, B.; LOEY, A.V.; FACHIN, D.; VERLENT, I.; HENDRICKX, I. M. Partial purification, characterization, and thermal and high-pressure inactivation of pectin methylesterase from carrots (Daucus carrota L.). Journal of Agricultural and Food Chemistry, Washington, v. 50, n. 19, p. 5437-5444, 2002b.

MACÁRIO, A.; MOLINER, M.; CORMA, A.; GIORDANO, G. Increasing stability and productivity of lipase enzyme by encapsulation in a porous organicinorganic system. Microporous Mesoporous Materials, Norway, v. 118, n. 1-3, p. 334-340, 2009.

MILETIC, N.; VUKOVI, Z.; NASTOSOVI, A.; LOOS, K. Macroporous poly(glycidyl methacrylate-ethylene glycol dimethacrylate) resins-versatile immobilization supports for biocatalysts. Journal of the Molecular Catalysis. B, Netherlands, v. 56, n. 1, p. 196-201, 2009.

OLIVEIRA, A. C.; VALENTIM, I. B.; GOULART, M. O. F.; SILVA, C. A.; BECHARA, E. J. H.; TRESIVAN, M. T. S. Fontes vegetais naturais de antioxidantes. Química Nova, São Paulo, v. 32, n. 3, p. 689-702, 2009.
OLIVEIRA, M. M.; CAMPOS, A. R. N.; GOMES, A. R. N.; GOMES, J. P.; SILVA, F. L. H. Isotermas de sorção do resíduo agroindustrial de casca do abacaxi (Ananás comosus L. Mer), Revista Brasileira de Engenharia Agrícola e Ambiental, Campina Grande, v. 9, n. 4, p. 565569, 2005.

PELIZER, L. H.; PONTIERI, M. H.; MORAES, I. O. Utilização de resíduos agro-industriais em processos biotecnológicos com perspectiva de redução de impacto ambiental. Journal of Technology Management \& Innovation, Santiago, v. 2, n. 1, p, 118-127, 2007.

PORRO, M.; VITI, S.; ANTONI G.; SALETTI, M. Ultrasensitive silver staining method for detection of protein on polyacrylamide gels and immunoprecipitates on agarose gels. Analytical Biochemistry, New York, v. 127, n. 2, p. 316-321, 1982.

PRADO, I. N.; LALLO, F. H.; ZEOULA, L. M.; NETO, S. F. C.; NASCIMENTO, W. G.; MARQUES, J. A. Níveis de substituição da silagem de milho pela silagem de resíduos industrial de abacaxi sobre o desempenho de bovinos confinados. Revista Brasileira de Zootecnia, Viçosa, v. 32, n. 3, p. 737-744, 2003.

PRASANNA, V.; PRABHA, T. N.; THARANATHAN, R. N. Multiple forms of polygalacturonase from mango (Mangifera indica L. cv Alphonso) fruit. Food Chemistry, Barking, v. 95, n. 1, p. 30-36, 2006.

RAMOS, E. Empresa desenvolve enzimas. 2012. Disponível em: <http://www.bioenzima.com.br/page_4. html >. Acesso em: 25 ago. 2012.

RESENDE, J. M.; CHITARRA, M. I. F.; MALUF, W. R.; CHITARRA, A. B.; SAGGIN, O. J. Atividade de enzimas pectinametilesterase e poligalacturonase durante o amadurecimento de tomates do grupo multilocular. Horticultura Brasileira, Campinas, v. 22, n. 2, p. 206212, 2004.

ROGÉRIO, M. C. P.; BORGES, I.; NEIVA, J. N. M.; RODRIGUES, N. M.; PIMENTEL, J. C. M.; MARTINS, G. A.; RIBEIRO, T. P.; COSTA, J. B.; SANTOS, S. F.; CARVALHO, F. C. Valor nutritivo do resíduo da indústria processadora de abacaxi (Ananás comosus L.) em dietas para ovinos. Consumo, digestibilidade aparente e balanços energético e nitrogenado. Arquivos Brasileiros de Medicina Veterinária e Zootecnia, Belo Horizonte, v. 59, n. 3, p. 773-781, 2007.

UENOJO, M.; PASTORE, G. M. Pectinases: aplicações industriais e perspectivas. Química Nova, São Paulo, v. 30, n. 2, p. 388-394, 2007.

WEBER, K.; OSBORN, M. The reability of molecular weight determination by dodecyl sulfate-polyacrylamide gel electrophoresis. The Journal of Biological Chemistry, v. 244, n. 16, p. 4406-4412, 1969. 